\title{
Obesity and its Correlates among Junior High School Children in the Accra Metropolis
}

\author{
Annan-Asare $\mathrm{J}^{* 1}$, Asante $\mathrm{M}^{2}$ and Amoah $\mathrm{AGB}^{3,4}$ \\ ${ }^{1}$ Department of Nutrition and Dietetics, School of Allied Health Sciences, University of Health and Allied Sciences, \\ Ho, Ghana, West-Africa \\ ${ }^{2}$ Department of Dietetics, School of Biomedical and Allied Health Sciences, College of Health Sciences, University of \\ Ghana, Legon-Accra, West-Africa \\ ${ }^{3}$ Department of Medicine Therapeutics, University of Ghana Medical School, Accra, Ghana, West-Africa \\ ${ }^{4}$ National Diabetes Management and Research Centre, Korle Bu Teaching Hospital, Korle Bu. Accra, Ghana, West- \\ Africa
}

${ }^{*}$ Corresponding author: Annan-Asare J, Department of Nutrition and Dietetics, School of Allied Health Sciences, University of Health and Allied Sciences, Ho, Ghana, Africa, Tel: +233 502908739, E-mail: jonathan_ asare@yahoo.com

Citation: Annan-Asare J, Asante M, Amoah AGB (2017) Obesity and its Correlates among Junior High School Children in the Accra Metropolis. J Nutr Health Sci 4(2): 206. doi: 10.15744/2393-9060.4.206

Received Date: July 04, 2017 Accepted Date: August 04, 2017 Published Date: August 08, 2017

\begin{abstract}
The prevalence of obesity is on the increase worldwide due to changes in diet and physical activity patterns. Childhood obesity is now a major public health challenge in advanced economies. Obesity in childhood tends to persist into adulthood and to predispose to noncommunicable diseases. There is little data on childhood obesity and its correlates and determinants in sub-Saharan Africa. A crosssectional study was carried out using simple random sampling technique to select 260 junior high school children aged 11-15 years from six basic schools $(\mathrm{n}=768)$ from three different socioeconomic (low, middle, high) areas of Accra, the capital city of Ghana. Demographic and physical activity data of the children were obtained with the aid of a questionnaire and height and weight were measured with subjects in light clothing and without shoes to determine body mass index (BMI). Food consumption pattern was assessed using a 3-day 24-h recall and a food frequency questionnaire. The prevalence of obesity in the entire cohort, girls and boys were $26.5,27$ and $26 \%$, respectively $(\mathrm{p}=0.34)$. The prevalence of obesity in low, middle and high class schools were $3.5,14.2$ and $8.8 \%$, respectively ( $\mathrm{p}=0.001$ ). Multivariate regression model showed significant positive correlations between BMI and age, female gender, fast food intake and the location of schools $(\mathrm{p}<0.05)$. There was no association between physical activity level and BMI $(\mathrm{p}=0.303)$. The mean intakes of energy, protein, fats and carbohydrates were $2074.4 \mathrm{kcal} \pm 699.0,75.5 \mathrm{~g} \pm 77.3,70.6 \mathrm{~g} \pm 29.3$ and $293.8 \mathrm{~g} \pm 106.5$, respectively (p $>0.05)$. Frequency of consumption of fruits and vegetables were 35.4 and 30.4\%, respectively $(\mathrm{p}<0.05)$. Obesity was found to be relatively high in Ghanaian adolescents in the Accra area. Female gender, age, economic class of children and very frequent consumption of fast foods were associated with higher BMI. Policies and programmes to promote healthy eating habits in children may prove beneficial.
\end{abstract}

Keywords: Childhood Obesity; Adolescents; BMI; Physical Activity; Dietary Intake; Socioeconomic; Sub-Saharan Africa

\section{Introduction}

Obesity is a complex, multi-factorial metabolic condition which is a result of the interactions between genetic and environmental factors, including dietary behaviors and nutrient exposures [1]. Obesity is defined as abnormal or excessive fat accumulation that presents a risk to health [2]. Obesity arises due to sustained positive energy balance that eventually ends in the accumulation of fat.

The World Health Organization reported that globally, obesity has reached epidemic proportions with about 1.9 billion adults classified as overweight, with at least 600 million of these being obese. This means approximately one-sixth of the world's population is overweight. Overweight/obesity therefore constitutes a public health crisis that contributes to a number of chronic diseases, disability and premature mortality $[3,4]$. Over the last few years obesity in childhood and adolescence has also increased at a dramatic pace in industrialized, as well as, many developing countries [4,5-7].

Globalization and increase in economic growth has led many developing countries including Ghana to undergo important demographic, epidemiological and nutrition transitions. Changes in dietary and physical activity patterns as a result of urbanization and increase in income affect health. The traditional Ghanaian diet which is rich in grains, legumes, fruits, and vegetables seems to 
be changing into a "Western" dietary pattern. The "new" diet is typically lower in dietary fibre, higher in saturated and trans fat and animal products, and includes more refined sugars and more processed foods. Adolescents seem to favour these processed and/or convenience foods more frequently. The consumption of more fatty foods with less fruits and vegetables coupled with a reduction in physical activity will result in overweight or obesity. Obesity in childhood predisposes to obesity in adults. Obesity is a major risk factor for chronic diseases and statistical data indicate that childhood obesity appears to be on the increase in Ghana. The 2014 Ghana Demographic and Health Survey (DHS) data demonstrated that the prevalence of obesity or overweight among adult (non-pregnant) women, aged 15-59, across the country increased by $30 \%$ in 2008 to $40 \%$ in 2014 . Importantly, the 2014 Ghana DHS data (WHO sponsored national obesity survey, 2014) showed that the proportion of overweight/obese women is positively correlated with women's age; this proportion increases from 9\% among women age 15-19 to 56\% for women age 40-49. Again, in both national studies Greater Accra Region had the highest overweight and obesity rates and women constituted a high-risk group (57\% versus 12\%) compared to the Northern Region.

In the light of the above, it is suggested that since the increasing obesity rates in Ghana are mainly linked to urbanization, modernization, affluence and changing lifestyles (in particular sedentary occupations and consumption of a wider diversity of local and foreign foods), there is the need for families to set aside time for healthy meals, physical activity whilst limiting television viewing, computer and video game use. Recommendations for childhood physical activity in children 5-18 years are a minimum of 60 minutes per day of moderate to vigorous physical activity [8]. Besides these, it is also recommended that schools should fund mandatory physical education, establish stricter standards for school lunch programmes, eliminate unhealthy foods-e.g. fast foods, soft drinks and candy from fast food vendors, joints or restaurants and provide healthy snacks through concession stands. To our knowledge, there is little or no information available on the prevalence of overweight and obesity and their correlates among junior high school children across different social classes in the Accra Metropolis. Therefore, this present study aimed to determine the prevalence and correlates of overweight and obesity among adolescents (aged 11-15 years) attending junior high schools (public and private) in the Accra Metropolitan area. Information derived from this study will be used to educate and plan intervention strategies to reduce adolescent obesity in Accra.

\section{Materials and Methods}

\section{Research Design and Target Population}

A cross-sectional study was employed to enable comparison of several children from the different age groups and social classes within a limited period. The population of interest in this study covered all pupils between the ages of 11 to 15 years schooling in neighbourhoods categorised as first (same as A class), second (same as B class) and third (same as C class) class areas. The choice of the population was based on the assumption that the participants would be living in, around or not too far from their school's neighbourhoods. The study was carried out in randomly selected first, second and third class residential areas in the Accra Metropolis based on income zones as outlined in the Local Government Bulletin (2002) of the Accra Metropolitan Assembly. Two junior high (one private and one public) schools located in each of the three income zones were randomly selected from the Metropolitan Education Unit list of schools to serve as study sites.

Two schools each located in neighbourhoods with high socio-economic status (i.e. first class school), middle socio-economic status (second class school) and low socio-economic status (third class school) areas served as study sites, respectively.

\section{Sampling Method/Technique}

Simple random sampling method was employed for this study. To achieve this, all schools and children in selected income zones were given equal chance to participate in the study. Codes were given to schools in each income zone. Six coded and folded sheets were then picked from a basket to serve as study sites (schools). Children within the age bracket were picked by selecting folded sheets with YES and NO options. All children who picked YES were included in the study. Children with eating disorders including dieting, physical limitations, other co-morbid conditions, or being treated by medications that could affect eating or physical activity were excluded.

\section{Sample Size Determination}

The minimum sample size was determined using the prevalence study formula

$$
\mathrm{n}=\frac{\mathrm{z}^{2}(\mathrm{pq})}{\mathrm{d}^{2}}
$$

Where $\mathrm{z}=$ value for confidence interval set at $1.96, \mathrm{~d}=$ margin of error set at 0.02 , estimated prevalence ( $\mathrm{p}$ ) of adolescent obesity in Ghana, 2.5\%. Hence, $\mathrm{n}=234$ (minimum sample size). To allow for a non-response/drop-out rate, $10 \%$ of 234 was computed to arrive at a final sample size 257 which was rounded off to 260 .

\section{Data Collection}

All the children were assisted to complete the child questionnaire and physical measurement of their height and weight were taken. Physical activity levels were assessed verbally and all parents/guardians were asked to complete a parent questionnaire. Information on household income, ethnicity, marital status, and education level of parents were obtained from the parents questionnaire. 
Socio-Demographic Data: Data on gender, age, school grade were collected with an interviewer-administered structured questionnaire.

Anthropometric Measurements: Height and weight were measured for each subject. Child height was measured using a standardized protocol. Height was measured without shoes and recorded to the nearest $0.1 \mathrm{~cm}$ using a portable stadiometer (Seca, Hamburg, Germany). Respondents had their feet together with their heels against the measuring board. They stood erect without tipping their heads up or down and the top of their ears and outer corner of their eyes were in a line parallel to the floor (Frankfort plane).

Participants' weight was measured using a Seca 770 floor digital scale (Seca, Hamburg, Germany) which was periodically calibrated for accuracy using known weights. Subjects were in minimal clothing, with shoes removed, and made to stand on the scale with feet fully on the scale. It was ensured that subject's weight was evenly distributed on both feet. Subjects stood upright, hands by their sides and head levelled with eyes looking straight ahead. Weight was then recorded to the nearest $0.1 \mathrm{~kg}$.

Dietary Behaviour: Food intake was assessed using three-day (two-week days and one week-end day) 24 hour recalls and a food frequency questionnaire. The 24 hour recall was used to assess usual dietary intake of all meals and snacks and food preparation techniques. Graduated food models were used to aid in portion size estimation. Obtained foods were entered and analyzed using Microsoft excel spread sheet. The United States Department of Agriculture (2010) tables were employed for the analysis of nutrient composition including macronutrient content of foods. A Food frequency questionnaire was used to assess the frequent intake of fatty foods and fast foods. The food frequency questionnaire was pre-tested before the main study was carried out.

Physical Activity Data: Study participants completed the Global Physical Activity Questionnaire. Physical activity was evaluated using questions based on the simplified and modified Global Physical Activity Questionnaire (GPAQ) covering light, moderate and vigorous activities. The light physical activities included time spent sitting at a desk, visiting friends, reading, travelling on a bus or sitting or lying down to watch television, playing video or computer games. Moderate activities referred to ones that take a little extra effort and made the child breathe somewhat harder than normal. It included activities like walking, sweeping, mopping and swimming. Vigorous physical activities were the types that take hard physical effort and made the child breathe much harder than normal and it included activities like running, skipping rope and gymnastics.

The physical activity score was obtained by conducting a validated activity interview for children. A modified Global Physical Activity Questionnaire was used in a seven (7) day recall of all activities including type, duration and intensity. Memory-enhancing questions and lists of usual juvenile activities were used to help with recall. The amount of time in hours each subject spent in light, moderate and vigorous activity was then calculated. The activities were given intensity values based on metabolic equivalents (METS). One MET requires $3.5 \mathrm{ml}$ of oxygen per kilogram $(\mathrm{kg})$ of body weight per minute. This equals approximately $1 \mathrm{kcal} /$ $\mathrm{kg} / \mathrm{h}$. For example, an activity such as walking would expend $4 \mathrm{kcal} / \mathrm{kg} / \mathrm{h}$ or require $4 \mathrm{METS}$. To make the energy cost calculations, light activities were assigned an average of 1.5 METS, moderate activities 4 METS and vigorous activities 8 METS. To estimate the average time ( $\mathrm{min} /$ day) spent on various activities the reported amount of time ( $\mathrm{min} /$ day) spent in that activity (lasting more than ten (10) minutes was multiplied by the number of days per week it was performed, and then divided by seven (7) to estimate average time spent on a typical weekday. To calculate the activity score, the minutes spent in each activity category was multiplied by the average MET for the category and summed over all categories. The children were categorised as moderately active when they earned between 600METS and 1500 METS for vigorous activities. Those whose total vigorous activity was less than 600METS and more than 1500 METS were described as less and highly active, respectively.

\section{Statistical Analysis}

Data analyses were done using the Statistical Package for Social Sciences (version 16.0; SPSS, Chicago, IL) and Microsoft excel spread sheet software. Descriptive statistics (means and standard deviations) were calculated for continuous variables while proportions were calculated for categorical variables. Differences in the various indicators -nutritional status and socio-economic status as well as other variables of interest (energy intake, activity score, etc.) - were tested for statistical significance using analysis of variance (ANOVA) and crosstabs. Logistic regression analysis was used to determine the influence of socioeconomic status (parents' educational level and monthly income), children's gender and age on parents' ability to accurately identify their children's weight status. Multiple linear regression analysis was used to assess the effects the individual independent variables had on the dependent variable as well as associations between the dependent variable and the independent variables. The dependent variable was body mass index and the independent variables were age, gender, carbohydrate, fat and energy intake, fast food intake, total physical activity (activity score) and socioeconomic status (income and educational levels of parents, and child's school location). Body mass index (BMI) was determined from the weight and height measurements. Relative weight (BMI) was categorised as follows: underweight, $<-1.64 \mathrm{z}$-score or the $5^{\text {th }}$ percentile; normal weight, -1.64 and $1.04 \mathrm{z}$-score (i.e. $5^{\text {th }}$ and $85^{\text {th }}$ percentile); overweight, 1.04 and $1.64 \mathrm{z}$-score $\left(85^{\text {th }}\right.$ and $95^{\text {th }}$ percentile); and obesity, $>1.64 \mathrm{z}$-score ( $95^{\text {th }}$ percentile). The level of statistical significance was set at $\mathrm{p}<0.05$.

\section{Ethics}

The study was undertaken after the Ethics Review Board of the School of Biomedical and Allied Health Sciences, College of Health 
Sciences, University of Ghana, has granted approval (Ethical Identification Number: SAHS-Et/10103833/AA/26A/2010-2011). Permission was sought from the Accra Metropolitan Area Education Unit before the study began. Informed consent was obtained from each subject and their caregiver before participation.

\section{Results}

A total of two hundred and sixty (260) children participated in the study, 54.2\% were females and $45.8 \%$ were males. Majority of the children (50.8\%) were aged 13-14.9 years, followed by those in the 11-12.9 years age group (33.1\%). A few (16.2\%) were aged 15 years. Most of the respondents (41.2\%) were in grade seven (7) as shown in Table 1.

\begin{tabular}{|c|c|c|c|c|}
\hline & $\begin{array}{c}\text { First class } \\
(\mathbf{n}=\mathbf{8 2})\end{array}$ & $\begin{array}{c}\text { Second class } \\
(\mathbf{n}=\mathbf{9 4})\end{array}$ & $\begin{array}{c}\text { Third class } \\
(\mathbf{n}=\mathbf{8 4})\end{array}$ & $\begin{array}{c}\text { Total } \\
(\mathbf{n}=\mathbf{2 6 0})\end{array}$ \\
\hline \multicolumn{5}{|c|}{ Gender } \\
\hline Female & $45(54.9)$ & $54(57.4)$ & $42(50.0)$ & $141(54.2)$ \\
\hline Male & $37(45.1)$ & $40(42.6)$ & $42(50.0)$ & $119(45.8)$ \\
\hline \multicolumn{5}{|c|}{ Age, years } \\
\hline $\mathbf{1 1}-\mathbf{1 2}$ & $30(36.6)$ & $45(47.9)$ & $11(13.1)$ & $86(33.1)$ \\
\hline $\mathbf{1 3} \mathbf{- 1 4} \mathbf{4}^{\star}$ & $41(50.0)$ & $36(38.3)$ & $55(65.5)$ & $132(50.8)$ \\
\hline $\mathbf{1 5}$ & $11(13.4)$ & $13(13.8)$ & $18(21.4)$ & $42(16.2)$ \\
\hline \multicolumn{5}{|c|}{ Grade } \\
\hline $\mathbf{7}$ & $34(41.5)$ & $36(38.3)$ & $37(44.1)$ & $107(41.2)$ \\
\hline $\mathbf{8}$ & $33(40.2)$ & $33(35.1)$ & $36(42.9)$ & $102(39.2)$ \\
\hline $\mathbf{9}$ & $15(18.3)$ & $25(26.6)$ & $11(13.1)$ & $51(19.6)$ \\
\hline
\end{tabular}

Data are presented as $\mathrm{n}(\%)$

${ }^{*}$ A significantly higher proportion of the children were in the $13-14$ years age group, $\mathrm{P}<0.05$

Table 1: Demographic characteristics of children by school location

Table 2 illustrates the differences in physical activity levels among children from the different classes of schools. The results indicated that $55.4 \%$ of all respondents were highly active with a corresponding $40.2 \%, 61.1 \%$, and $72.6 \%$ for the first class, second class and third class schools, respectively. There was a significant difference $(\mathrm{p}=0.018)$ in the mean levels of light activity across the different classes of schools.

\begin{tabular}{|c|c|c|c|c|}
\hline & $\begin{array}{l}\text { First class } \\
\quad(\mathbf{n}=\mathbf{8 2})\end{array}$ & $\begin{array}{l}\text { Second class } \\
\quad(n=94)\end{array}$ & $\begin{array}{l}\text { Third class } \\
(\mathrm{n}=84)\end{array}$ & $\begin{array}{c}\text { Total } \\
(n=260)\end{array}$ \\
\hline \multicolumn{5}{|c|}{ Physical Activity } \\
\hline Light $^{\mathrm{b}}$ & $5679.5 \pm 1826.1$ & $5027.0 \pm 1789.9$ & $4998.2 \pm 1601.1$ & $5223.0 \pm 1763.8$ \\
\hline Moderate & $2573.0 \pm 2464.0$ & $2203.1 \pm 1702.2$ & $2513.5 \pm 1633.0$ & $2420.1 \pm 1954.7$ \\
\hline Vigorous & $2191.9 \pm 2710.7$ & $2974.0 \pm 3992.4$ & $3306.8 \pm 3635.2$ & $2834.8 \pm 3530.8$ \\
\hline Total activity & $10440.0 \pm 4926.7$ & $10200.0 \pm 5314.9$ & $10820.0 \pm 5066.6$ & $10480.0 \pm 5101.6$ \\
\hline \multicolumn{5}{|c|}{ Activity Ratings ${ }^{c}$} \\
\hline Low & $27(32.9)$ & $20(21.3)$ & $13(15.5)$ & $60(23.1)$ \\
\hline Moderate & $22(26.8)$ & $24(25.5)$ & $10(11.9)$ & $56(21.5)$ \\
\hline High $^{*}$ & $33(40.2)$ & $50(53.2)$ & $61(72.6)$ & $144(55.4)$ \\
\hline
\end{tabular}

${ }^{a}$ Values are means \pm SD

${ }^{\mathrm{b}}$ Mean values of light activity are significantly different, $\mathrm{p}=0.018$

${ }^{c}$ Values are presented as $\mathrm{n}(\%)$

${ }^{*} \mathrm{P}<0.05$

Table 2: Physical activity levels (metabolic equivalents, METS-minutes per week) and activity ratings distribution among children by school location

Analysis of variance of the macronutrients intake among the respondents indicated no significant differences in the mean intakes of energy, protein, carbohydrates and fats across the different classes of schools (Table 3). On average proteins, fats and carbohydrates contributed $13.8 \%, 30.2 \%$, and $56.0 \%$ respectively to the total calories (Table 3 ). Also, the mean fat intake of children in Second class schools $(72.7 \pm 34.5 \mathrm{~g})$ tended to be higher but not significantly different from intakes of children in both third class $(70.8 \pm 24.1 \mathrm{~g})$ and first class schools $(67.9 \pm 27.8 \mathrm{~g})$. In addition, the mean fat intakes of third class schools children tended to be higher compared to intakes of children in first class schools.

Reported intakes of fruits were significantly higher in C class (third class schools) participants compared to both B class (second class schools) and A class (first class schools) participants (40.5\% vs. $35.4 \%$ or $30.9 \%$, p=0.030), respectively. There was a significant difference $(\mathrm{p}=0.009)$ in the reported intake of fatty meat (e.g. sausage, "khebabs") across all three classes of schools with majority 
of children (42.6\%) from the B class schools (second class) reporting the highest intakes (Figure 1).

\begin{tabular}{|c|c|c|c|c|c|}
\hline & $\begin{array}{l}\text { First class } \\
\quad(\mathbf{n}=\mathbf{8 2})\end{array}$ & $\begin{array}{l}\text { Second class } \\
\quad(n=94)\end{array}$ & $\begin{array}{l}\text { Third class } \\
(\mathrm{n}=84)\end{array}$ & $\begin{array}{c}\text { Total } \\
(n=260)\end{array}$ & $\begin{array}{c}P \text { (Significant } \\
\text { level) }\end{array}$ \\
\hline $\begin{array}{l}\text { Energy intake } \\
\quad \text { (kcal) }\end{array}$ & $2027.7 \pm 692.6$ & $2174.3 \pm 812.0$ & $2008.1 \pm 547.5$ & $2074.4 \pm 699.0$ & 0.219 \\
\hline Protein $(\mathrm{g})$ & $69.2 \pm 24.1$ & $87.4 \pm 124.4$ & $68.4 \pm 21.6$ & $75.5 \pm 77.3$ & 0.176 \\
\hline Protein (\% energy) & $13.7 \pm 2.1$ & $14.0 \pm 2.7$ & $13.6 \pm 2.3$ & $13.8 \pm 2.4$ & \\
\hline Fat $(\mathrm{g})$ & $67.9 \pm 27.8$ & $72.7 \pm 34.5$ & $70.8 \pm 24.1$ & $70.6 \pm 29.3$ & 0.555 \\
\hline CHO (g) & $29.8 \pm 6.6$ & $29.7 \pm 6.9$ & $31.2 \pm 5.8$ & $30.2 \pm 6.5$ & \\
\hline CHO (\% energy) & $290.5 \pm 108.8$ & $309.2 \pm 122.4$ & $279.7 \pm 81.0$ & $293.8 \pm 106.5$ & 0.172 \\
\hline High $^{*}$ & $56.6 \pm 7.3$ & $56.3 \pm 8.0$ & $55.2 \pm 5.9$ & $56.0 \pm 7.2$ & \\
\hline
\end{tabular}

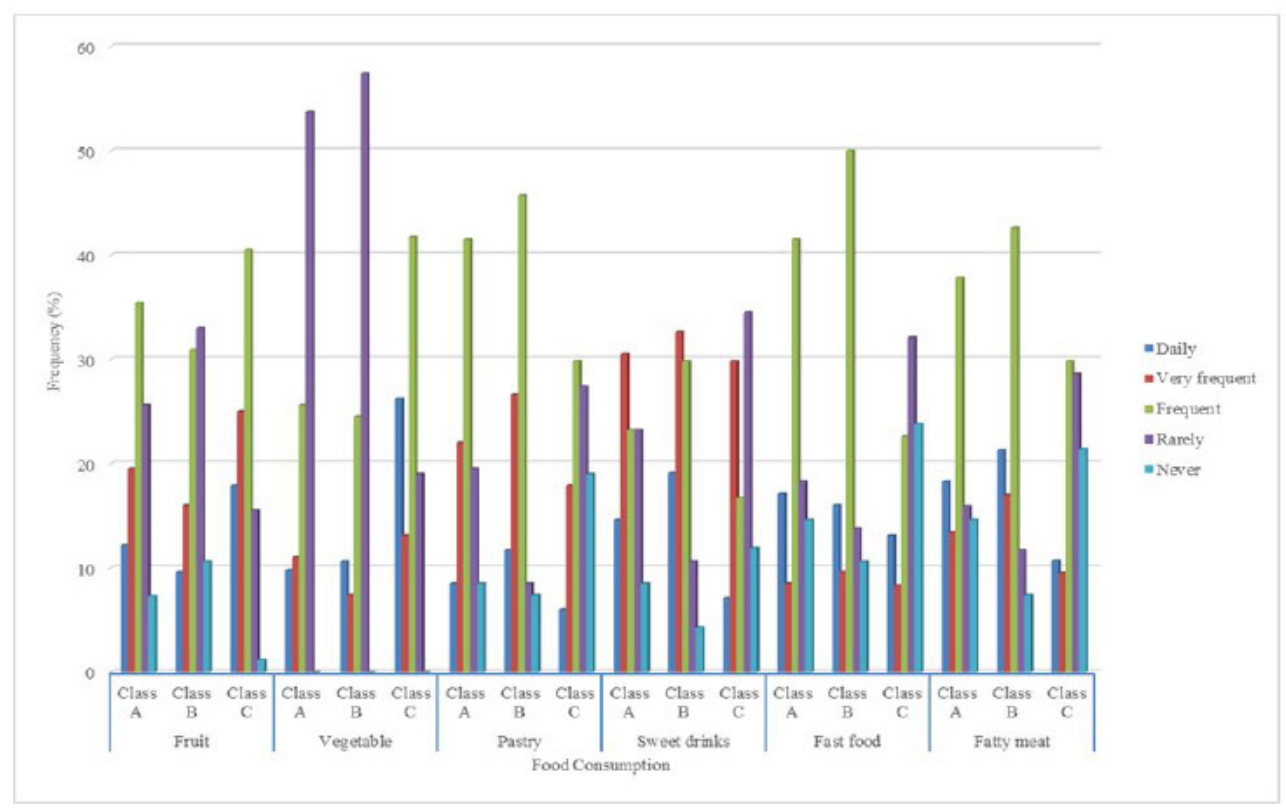

Figure 1: Comparison of the frequency of consumption of food among children by school location

Table 4 shows that the prevalence of overweight and obesity among the children was 59.4 and $53 \%$, respectively. The rates of overweight ( $33.3 \%$ vs. $26.1 \%$ ) and obesity (27\% vs. $26 \%$ ) were higher in females than males. There was also a significant difference $(\mathrm{p}=0.001)$ between the children's mean BMI-for-age (Table 4$)$.

\begin{tabular}{|c|c|c|c|c|}
\hline Variables & $\begin{array}{l}\text { First class } \\
\quad(n=82)\end{array}$ & $\begin{array}{l}\text { Second class } \\
\quad(n=94)\end{array}$ & $\begin{array}{l}\text { Third class } \\
(\mathrm{n}=\mathbf{8 4})\end{array}$ & $\begin{array}{c}\text { Total } \\
(n=260)\end{array}$ \\
\hline $\begin{array}{c}\text { BMI-for-age } \\
\text { z-score }^{\mathrm{a}}\end{array}$ & $1.24(1.1)^{*}$ & $1.65(1.1)^{*}$ & $0.50(1.1)^{*}$ & $1.15(1.2)^{*}$ \\
\hline \multicolumn{5}{|c|}{ Normal weight } \\
\hline Boys n (\%) & $13(35.1)$ & $13(35.1)$ & $31(73.8)$ & $57(47.9)$ \\
\hline Girls n (\%) & $15(33.3)$ & $13(24.1)$ & $28(66.7)$ & $56(39.7)$ \\
\hline \multicolumn{5}{|c|}{ Overweight } \\
\hline Boys n (\%) & $11(29.7)$ & $16(40.0)$ & $4(9.5)$ & $31(26.1)$ \\
\hline Girls n (\%) & $20(44.4)$ & $15(27.8)$ & $12(28.6)$ & $47(33.3)$ \\
\hline \multicolumn{5}{|c|}{ Obese } \\
\hline Boys n (\%) & $13(35.1)$ & $11(27.5)$ & $7(16.7)$ & $31(26.0)$ \\
\hline Girls n (\%) & $10(22.2)$ & $26(48.2)$ & $2(4.8)$ & $38(27.0)$ \\
\hline
\end{tabular}


Multivariate analysis showed that factors that significantly affected BMI in this study were children's age (A point increase in age accounts for 0.829 unit increase in BMI $(\mathrm{p}=0.002)$ ), gender of respondents (Being a female impacts 1.378 unit increase in BMI $(\mathrm{p}=0.022)$ than being a male), location of school (Enrolling in a school located in either high income zone (first class schools) or middle income zone (second class schools) impacts 2.601 or 4.471 unit increase, respectively in BMI ( $\mathrm{p}=0.001)$ ) and fast food intake (Consumption of fast food more than four times a week leads to 2.559 unit increase in BMI $(\mathrm{p}=0.035)$ ) $($ Table 5).

\begin{tabular}{|c|c|c|c|c|}
\hline Predictor variable & B & $\begin{array}{c}\text { Standard } \\
\text { error }\end{array}$ & Beta & $\begin{array}{c}\text { Significant } \\
\text { level }\end{array}$ \\
\hline Age (years) & .829 & .258 & .195 & $.002^{*}$ \\
\hline Female gender & 1.378 & .597 & .139 & $.022^{*}$ \\
\hline \multicolumn{5}{|c|}{ Social class $^{\mathrm{a}}$} \\
\hline A class school & 2.601 & .745 & .246 & $.001^{\star}$ \\
\hline B class school & 4.471 & .757 & .436 & $.001^{\star}$ \\
\hline \multicolumn{5}{|c|}{ Fast food intake ${ }^{b}$} \\
\hline Daily & 1.634 & 1.043 & .120 & .118 \\
\hline Very frequent & 2.559 & 1.204 & .148 & $.035^{*}$ \\
\hline Frequent & .670 & .882 & .066 & .448 \\
\hline Rarely & 1.342 & .954 & .111 & .161 \\
\hline \multicolumn{5}{|c|}{ Nutrient intake ${ }^{c}$} \\
\hline Carbohydrate (g) & .006 & .017 & .122 & .742 \\
\hline Fat (g) & .009 & .042 & .055 & .828 \\
\hline Energy & -.001 & .004 & -.183 & .738 \\
\hline Activity score & -.000 & .000 & -.061 & .303 \\
\hline \multicolumn{5}{|c|}{ Parents' Income ${ }^{\mathrm{d}}$} \\
\hline Below \$ 1000 & .358 & .772 & .029 & .643 \\
\hline Above $\$ 1000$ & .144 & .706 & .013 & .839 \\
\hline \multicolumn{5}{|c|}{ Parents' Education } \\
\hline JHS-SHS & -.023 & .522 & -.069 & .489 \\
\hline Tertiary & .026 & .303 & -.011 & .914 \\
\hline
\end{tabular}

BMI is the dependent variable

The reference category for social class is $\mathrm{C}$ class schools (schools located in low income zone)

${ }^{\mathrm{b}}$ The reference category for fast food intake is Never

'The reference category for Nutrient Intake is Protein

dThe reference category for Parent's Income is Low income

'The reference category for Parents' level of education is Never attended-Elementary school

$\mathrm{R}^{2}=.205: \Delta \mathrm{R}^{2}=.186(\mathrm{p}=0.001)$

${ }^{*} \mathrm{P}<0.05$

Table 5: The unstandardised and standardised regression coefficients for the variables entered into the model

\section{Discussion}

\section{Physical Activity Patterns, Sedentary Behaviour and Obesity}

The mean BMI z-score of the children in the three classes of schools was significantly different as the children came from different socioeconomic backgrounds, and had different physical activity patterns and levels. Sedentary lifestyle or lack of physical activity is thought to have at least as important a role as diet in the aetiology of obesity. In this study, children from the third class schools were more physically active than those from the second class schools and children from the first class schools were the least active, hence, many (57.3\% vs. $21.5 \%)$ obese children were found in first class schools than in third class schools. No association was found between BMI and physical activity which is consistent with findings from studies by Kettaneh, et al., and Stice, et al., who found no association between activity levels and measures of adiposity. A meta-analysis among samples of children and youth aged 3-18 years old in the UK found that physical activity effects on body mass index were small and were unlikely to be of clinical relevance $[9,10,11]$.

The literature has been inconsistent in the relationship between physical activity and weight and this could be because physical activity is only one aspect of energy balance. However, according to literature, the design of the study (that is, cross-sectional and prospective, observational cohort studies); the methods of data collection (that is, the use of physical activity questionnaire and the use of heart monitoring equipment) and finally the sample size may all have effect on the relationship between activity levels and weight gain $[9,10,12-14]$. Therefore, the present findings of no association between physical activity and adiposity might have been due to the relatively smaller sample size of two hundred and sixty respondents (260) compared to other studies with over 
thousand respondents, which resulted in significant associations between activity levels and weight gain. Another reason could be due to the physical activity questionnaire administered which was based on recall and which could be subjected to errors such as overestimation and underestimation of activities done.

\section{Dietary and Energy Intake among Children}

In this study, there were no significant differences in the consumption of proteins, carbohydrates, total fats and total energy across the different socioeconomic classes. However, children from second class schools had higher intakes of fat than their counterparts from the first and third class schools. Although participants from the first class schools consumed relatively less fat than those from third class schools, they had higher energy intakes and were physically less active too. The higher intake of carbohydrate by subjects from the first class schools may have contributed to their higher energy value compared to children from the third class schools and that may have led to many (57.3\% vs. $21.5 \%)$ of them being obese compared to participants from the third class schools. Thus, the total energy consumed, not total fat, may have contributed to the subjects' high body mass index. Other authors have also reported a similar pattern [15-17]. In contrast, Tucker, et al., carried out a study to ascertain the association between diet composition and body fat percentage as well as to examine the influence of gender, total energy intake, fitness, physical activity and parental body on the relationship between diet composition and adiposity in a sample of 262 children aged 9-10 years old [18]. Their results showed that fat intake, calculated as a percentage of total energy, was positively related to adiposity, before and after control for potential confounding variables, whiles percentage of energy derived from carbohydrate was inversely related to adiposity, before and after controlling for potential confounders. A randomized cross-sectional study by Guillaume et al., among 1028 children aged 6-12 years in the province of Luxembourg, Belgium also reported that total fat ( $\mathrm{p}=0.045)$ showed consistent positive correlations with body mass index while total energy intake showed no or weekly significant correlations with BMI in boys [19].

The discrepancy among studies may be due to smaller sample sizes or the involvement of children who do not have the ability to accurately report portion sizes or as observed in other studies, that obese individuals tend to underestimate their food intakes and overestimate their physical activity patterns [20-23]. Again, portion sizes have been reported to be underestimated by up to $52 \%$ or overestimated by up to $100 \%$ compared with the actual portion size regardless of the method used (standard portion sizes or food photographic atlas) or the age of the subjects (47 adults aged 17-82 years and 37 children aged 6-16 years). However, children were found to show greater errors using both the descriptions and the food atlas methods to determine portion sizes than in the older subjects aged 17 years and above. The findings seem to suggest that either an alternative method or a modification of the methods used in that study for estimating portion sizes in young subjects, for example standard food portion sizes for children of different ages, would be more appropriate [24].

\section{Dietary Habits of Adolescents}

Results from this study revealed that participants from the high income zone (first class schools) frequently consumed pastries, fatty meat and fast food and rarely consumed fruits and vegetables compared to their counterparts from the low class (third class schools) zone (Figure 1). Thus, their food consumption pattern showed less adherence to the traditional Mediterranean diet and an adoption of a more westernized diet compared with the low class group. According to Ham and Kim [25], daily consumption of fruit and vegetables is an important indicator of a healthy diet and the beneficial effect of lowered body mass index. It was observed in this study that participants from the low class zone (third class schools) consumed significantly higher amount of fruits and vegetables compared to those from the high income zone (first class schools) and therefore had fewer (21.5\% vs. 57.3\%) number of obese adolescents. This indicates that belonging to the lower-socioeconomic status group confers strong protection against obesity in low-income economies and can reduce or increase obesity in lower-middle income economies. This finding is similar to studies that reported associations of food groups with childhood overweight or obesity $[22,26,27]$. Epidemiological studies suggest that the consumption of high intake of fruits and vegetables is associated with the reduction of risk for cancer and protective against cardiovascular diseases, diabetes, obesity and cerebral vascular accidents [28].

However, the study also showed that the schools located in the middle income zone (second class) had more overweight and obese pupils than the high income zone schools (first class) and this may be due to differences in the frequency of consumption of some high caloric foods. The frequency of consumption of pastries, sweet drinks and candies, fatty meat and fast food were significantly slightly higher among the second class participants than their first class counterparts. This observation is in line with studies that have shown that greater intake of snacks and fast foods in adolescence contributes to weight gain and/or obesity [29-32]. This indicates that there might be a reversal of the socioeconomic gradient as obesity becomes a disease of the poor as depicted by other studies $[33,34]$.

The rates of overweight (33.3\% vs. $26.1 \%)$ and obesity ( $27 \%$ vs. $26 \%$ ) in this study were found to be higher in females than males. These rates are much higher than that recorded (boys: $10.9 \%$ vs. $2.4 \%$; girls: $17.5 \%$ vs. $4.8 \%$ ) by Armstrong, et al., [35]. This could be attributed to the increased intake of fast foods, sweets and sugar sweetened beverages among girls than in their male counterparts. In 2005, Schmidt and colleagues also found a positive association between higher frequency of fast-food intake with higher levels of energy intake and total fat among black and white adolescent girls in the United States [36]. 


\section{Lifestyle and Social Class on the Development of Overweight/Obesity}

The findings of the study showed that third class households had lower parental income and educational levels than second class households whilst first class households had the highest percentages in both parental income and educational levels. The mean BMI-for-age of the children in the three classes of schools was also significantly different as they came from different socioeconomic backgrounds, and had different physical activity patterns. It was observed that generally the prevalence of overweight/obesity was high, with $30.0 \%$ of the population being overweight and $26.5 \%$ obese. Overweight and obesity together in the six schools was about $57 \%$ of the study subjects. Obesity in the subjects studied was much higher than that recorded (8.1\%) by Armstrong, et al., among South African children aged 6-13 years. This prevalence rate confirms the literature explanation of an increasing prevalence of obesity in developing countries [35,37]. The fact that more than half of the study subjects were either overweight or obese is of concern in view of the increased morbidity and premature mortality that accompanies those conditions.

Participants from second class schools had the highest percentage of both overweight and obese rates (72.4\%) followed by participants from first class schools $(65.8 \%)$ and those from third class schools had the least (29.7\%). Children in third class schools were the most active followed by those from second class schools. Moreover, participants from the first class schools earned the highest marks for light (sedentary) activities. These findings are in line with similar studies that showed that parents and the family environment influenced food habits in a complex interactive way [38,39]. While low socioeconomic status and poor neighbourhoods have been associated with a higher prevalence of obesity and chronic diseases in developed nations, studies in Africa and other low-income countries have shown by contrast a strong positive relationship between obesity and high socioeconomic status [40-45].

\section{Conclusions}

The prevalence of overweight or obesity was highest in the middle-income neighbourhood schools (second class schools) with the low-income neighbourhood schools (third class schools) having the least prevalence. Results from this study therefore do not support the view that obese and overweight children are dominant in the high socioeconomic zones only, even though there was a significant difference in the mean body mass index across the different groups. It goes to show that subjects from the middleincome schools are in a state of nutrition transition and that obesity is becoming a problem of the poor.

There was no significant difference between the consumption of proteins, carbohydrates, fats and total energy across the different socioeconomic classes. These findings reinforce the notion that total calories and not fat intake has a significant effect on weight gain as there was no significant difference in the mean caloric intake across the different socioeconomic classes.

The study also showed a worrying increase in sedentary behaviour among children of high-income parents/guardians.

The multivariate-regression model for body mass index showed that there was no significant interaction between the dependent variable, body mass index and the independent variables-carbohydrate, fat and energy intake, activity, parental income and educational levels. However, the location of the school (socioeconomic status composition), age of child, female gender and intake of fast food more than four times a week had a significant impact on body mass index. Overweight and obesity are increasing among adolescents in the Accra metropolitan area. Female gender, increasing age of child, schools located in the high-middle class zones and very frequent consumption of fast food were associated with higher body mass index. Policies and programmes that promote healthy lifestyles and physical activity may prove beneficial.

\section{References}

1. Papoutsakis C, Dedoussis GV (2007) Gene-diet interactions in childhood obesity: paucity of evidence as the epidemic of childhood obesity continues to rise. Personalized Med 4: 133-46.

2. World Health Organization (2017) Global strategy on Diet, Physical activity and Health, Geneva, Switzerland.

3. World Health Organization (2017) Obesity and overweight, Geneva, Switzerland.

4. Ebbeling CB, Pawlak DB, Ludwig DS (2002) Childhood obesity: public-health crisis, common sense cure. Lancet 360: 473-82.

5. Jolliffe D (2004) Extent of overweight among US children and adolescents from 1971 to 2000. Int J Obes Relat Metab Disord 28: 4-9.

6. Lobstein T, Frelut ML (2003) Prevalence of overweight among children in Europe. Obes Rev 4: 195-200.

7. Wang Y, Monteiro C, Popkin BM (2002) Trends of obesity and underweight in older children and adolescents in the United States, Brazil, China, and Russia. Am J Clin Nutr 75: 971-7.

8. O’Malley G, Ring-Dimitriou S, Nowicka P, Vania A, Frelut ML, et al. (2017) Physical Activity and Physical Fitness in Pediatric Obesity: What are the First Steps for Clinicians? Expert Conclusion from the 2016 ECOG Workshop. Int J Exerc Sci 10: 487-96.

9. Kettaneh A, Oppert JM, Heude B, Deschamps V, Borys JM, et al. (2005) Changes in physical activity explain paradoxical relationship between baseline physical activity and adiposity changes in adolescent girls: the FLVS II study. Int J Obes 29: 586-93.

10. Stice E, Presnell K, Shaw H, Rohde P (2005) Psychological and behavioral risk factors for obesity onset in adolescent girls: a prospective study. J Consult Clin Psychol 73: 195-202.

11. Marshall SJ, Biddle SJ, Gorely T, Cameron N, Murdey I (2004) Relationships between media use, body fatness and physical activity in children and youth: a meta-analysis. Int J Obes Relat Metab Disord 28: 1238-46.

12. Stettler N, Signer TM, Suter PM (2004) Electronic games and environmental factors associated with childhood obesity in Switzerland. Obes Res 12: 896-903.

13. Gordon-Larsen P, Adair LS, Popkin BM (2002) Ethnic differences in physical activity and inactivity patterns and overweight status. Obes Res 10: 141-9. 
14. Berkey CS, Rockett HR, Field AE, Gillman MW, Frazier AL, et al. (2000) Activity, dietary intake, and weight changes in a longitudinal study of preadolescent and adolescent boys and girls. Pediatrics 105: E56.

15. D’Addesa D, D'Addezio L, Martone D, Censi L, Scanu A, et al. (2010) Dietary intake and physical activity of normal weight and overweight/obese adolescents. Int J Pediatr 2010: 785649.

16. Goran MI, Hunter G, Nagy TR, Johnson R (1997) Physical activity related energy expenditure and fat mass in young children. Int J Obes Relat Metab Disord 21: $171-8$

17. Dalton S (1997) The role of diet and exercise in weight management In: Overweight and Weight Management, Jones \& Bartlett Learning Publications, USA.

18. Tucker LA, Seljaas GT, Hager RL (1997) Body fat percentage of children varies according to their diet composition. J Am Diet Assoc 97: 981-6.

19. Guillaume M, Lapidus L, Lambert A (1998) Obesity and nutrition in children. The Belgian Luxembourg Child Study IV. Eur J Clin Nutr 52: $323-8$.

20. Nguyen VT, Larson DE, Johnson RK, Goran MI (1996) Fat intake and adiposity in children of lean and obese parents. Am J Clin Nutr 63: 507-13.

21. Randall E (1991) Measuring food use in school-aged children. J Sch Health 61: 201-3.

22. Basch CE, Shea S, Arliss R, Contento IR, Rips J, et al. (1990) Validation of mothers' reports of dietary intake by four to seven year-old children. Am J Public Health 80: 1314-7.

23. Livingstone MB, Black AE (2003) Markers of the validity of reported energy intake. J Nutr 133: 895S-920S.

24. Frobisher C, Maxwell SM (2003) The estimation of food portion sizes: a comparison between using descriptions of portion sizes and a photographic food atlas by children and adults. J Hum Nutr Diet 16: 181-8.

25. Ham E, Kim HJ (2014) Evaluation of fruit intake and its relation to body mass index of adolescents. Clin Nutr Res 3: 126-33.

26. Ludwig DS, Peterson KE, Gortmaker SL (2001) Relation between consumption of sugar-sweetened drinks and childhood obesity: a prospective, observational analysis. Lancet 357: 505-8.

27. Robinson TN (1999) Reducing children's television viewing to prevent obesity: a randomized controlled trial. JAMA 282: 1561-7.

28. Jiménez-Cruz A, Bacardí-Gascón M, Jones EG (2002) Consumption of fruits, vegetables, soft drinks, and high-fat-containing snacks among Mexican children on the Mexico-U.S. border. Arch Med Res 33: 74-80.

29. Viskaal-van Dongen M, Kok FJ, de Graaf C (2010) Effects of snack consumption for 8 weeks on energy intake and body weight. Int J Obes (Lond) 34: 319-26.

30. Bowman SA, Gortmaker SL, Ebbeling CB, Pereira MA, Ludwig DS (2004) Effects of fast-food consumption on energy intake and diet quality among children in a national household survey. Pediatrics 113: 112-8.

31. Gillis LJ, Bar-Or O (2003) Food away from home, sugar-sweetened drink consumption and juvenile obesity. J Am Coll Nutr 22: 539-45.

32. Thompson OM, Ballew C, Resnicow K, Must A, Bandini LG, et al. (2004) Food purchased away from home as a predictor of change in BMI z-score among girls. Int J Obes Relat Metab Disord 28: 282-9.

33. McLaren L (2007) Socioeconomic status and obesity. Epidemiol Rev 29: 29-48.

34. Fernald LC, Gutierrez JP, Neufeld LM, Olaiz G, Bertozzi SM, et al. (2004) High prevalence of obesity among the poor in Mexico. JAMA 291: 2544-5.

35. Armstrong ME, Lambert MI, Sharwood KA, Lambert EV (2006) Obesity and overweight in South African primary school children -- the Health of the Nation Study. S Afr Med J 96: 439-44.

36. Schmidt M, Affenito SG, Striegel-Moore R, Khoury PR, Barton B, et al. (2005) Fast-food intake and diet quality in black and white girls: the National Heart, Lung, and Blood Institute Growth and Health Study. Arch Pediatr Adolesc Med 159: 626-31.

37. Bar-Or O (2003) The Juvenile Obesity Epidemic: Strike Back with Physical Activity. Sports Sci Exchange 16: 89.

38. A Aranceta J, Pérez-Rodrigo C, Ribas L, Serra-Majem L (2003) Sociodemographic and lifestyle determinants of food patterns in Spanish children and adolescents: the enKid study. Eur J Clin Nutr 57: S40-4.

39. Story M, Neumark-Sztainer D, French S (2002) Individual and environmental influences on adolescent eating behaviors. J Am Diet Assoc 102: S40-51.

40. Sundquist K, Malmstrom M. and Johansson SE (2004) Neighbourhood deprivation and incidence of coronary heart disease: a multilevel study of 2.6 million women and men in Sweden. J Epidemiol Community Health 58: 71-7.

41. Lopez RP (2007) Neighborhood risk factors for obesity. Obesity (Silver Spring) 15: 2111-9.

42. Fezeu L, Minkoulou E, Balkau B, Kengne AP, Awah P, et al. (2006) Association between socioeconomic status and adiposity in urban Cameroon. Int J Epidemiol 35: $105-11$.

43. Christensen DL, Eis J, Hansen AW, Larsson MW, Mwaniki DL, et al. (2008) Obesity and regional fat distribution in Kenyan populations: impact of ethnicity and urbanization. Ann Hum Biol 35: 232-49.

44. Kuga S, Njelekela M, Noguchi T, Kanda T, Yamori M, et al. (2002) Prevalence of overweight and hypertension in Tanzania: special emphasis on resting energy expenditure and leptin. Clin Exp Pharmacol Physiol Suppl 29: S23-6.

45. Kain J, Vio F, Albala C (2003) Obesity trends and determinant factors in Latin America. Cad Saude Publica 19: S77-86. 


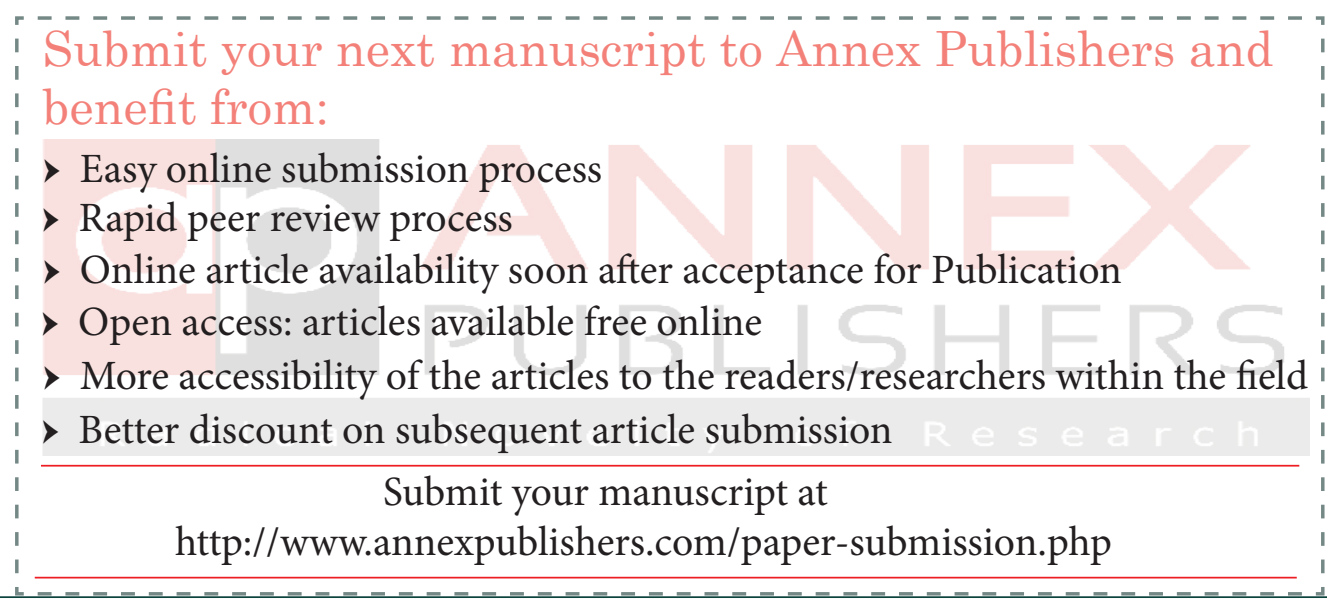

